\title{
THE EFFECT OF GROWING MEDIA AND HUMIC ACID TREATMENTS ON SOME PLANT PROPERTIES OF PURSLANE (Portulaca oleracea L.)
}

\author{
UgUR, A. ${ }^{1 *}-$ KocAmanoglu, C. ${ }^{2}$ \\ ${ }^{1}$ Agricultural Faculty, Department of Horticulture, Ordu University, 52200 Ordu, Turkey \\ ${ }^{2}$ Ordu Eskipazar Agricultural Credit Cooperative, 52100 Ordu, Turkey \\ *Corresponding author \\ e-mail: atnanugur@gmail.com; phone: +90-452-226-5200 -6237; fax: 90-452-234-6632
}

(Received $4^{\text {th }}$ May 2021; accepted $3^{\text {rd }}$ Sep 2021)

\begin{abstract}
Growing medium in soilless culture is important due to its effects on plant nutrition. In this study, the effects of growing environment and humic acid on yield and quality in purslane cultivation were investigated. The study was carried out in laboratories of Ordu University, Department of Horticulture and under greenhouses conditions (Merzifon provinces). Peat, perlite medium, 2:1 peat/perlite, 1:1 peat/perlite and 1:2 peat/perlite mixtures were used as growing medium in plastic sowing pot. Seeds were sown on the 6th of April. Throughout the study, all cultural processes were carried out to ensure that the crops reached marketable harvest size and plants were harvested on 24 May. The yield, shoot height, shoot diameter, oxalic acid and nitrate contents were determined for the harvested plants. Plant yields varied between 1957-3113 g per square meters depending on the growing medium. Parallel to the humic acid application dose, plant yield increased by $6.21-12.08 \%$. Similarly, the shoot height, shoot diameter and leaf oxalic acid contents increased with humic acid applications. Leaf nitrate contents were determined with $1512 \mathrm{mg} / 100 \mathrm{~g}$ in the lowest 1:1 peat/perlite medium. The highest nitrate value was determined as $2343 \mathrm{mg} / 100 \mathrm{~g}$ nitrate content in $100 \%$ perlite medium.
\end{abstract}

Keywords: leaf, nitrate, oxalic acid, Portulaca oleracea L., quality

\section{Introduction}

Purslane (Portulaca oleracea L.) is an annual herbaceous plant of Portulacaceae family. Purslane is a common weed and grows abundantly in vegetable gardens as it gets hotter via generating various tiny, black poppy-like seeds. The plant has found a large growing area in tropical and subtropical regions throughout the world as it grows fast, is self-compatible and generates various seeds that do not fade away for a long time. Called purslane in USA, the plant is also known as portulak, porcellana, glistrida, antrakla, adrahni, rigla, verdolaga, pigweed, beldroega, little hogweed, red root, tuchenitsa, pursle and semizotu in different parts of the world. There are records and documents indicating that the plant has been used in the Arabian Peninsula and Mediterranean basin since the Middle Age. The plant was called as "mad vegetable" in the Middle Age as it shoots and grew fast. Purslane has stood out in the recent years due to its content of phytochemicals, vitamins and minerals (Simopoulos et al., 1992; Palaniswamy et al., 2000; Petropoulos et al., 2016; Alu'datt et al., 2019). It's preventing oxidation and thus antioxidant capacity enhancing properties have been determined in the oil industry (Mousavi et al., 2015). It is used in public health due to its antitumor, hypoglycemic, antiscorbutic, antiseptic, antispasmodic, diuretic, antioxidant, antidiabetic, antibacterial, antitussive, antiinflammatory and wound healing properties (Dkhil et al., 2011). On the other hand, experimental studies were carried out on its medical effects. As it contains alpha linolenic acid, which is omega-3 oil acid found in fish and certain algae, its consumption has risen 
(Simopoulos et al., 1992; Palaniswamy et al., 2002). Its consumption is more preferred compared to fish as it has a more reasonable odor, is affordable and grown in plenitude in any ecological environment. It is generally consumed like spinach in Turkish cuisine; used in patties with different types of cheese and in salads and garnitures and as an appetizer with garlic and yoghurt. However, purslane contains a significant amount of oxalic acid (Palaniswamy et al., 2004). Normally all plants contain oxalic acid but certain types especially greens have a higher oxalic acid content. Oxalic acid generates insoluble salts by combining with acid iron and calcium and prevents their usefulness. Especially people with kidney diseases should be careful while consuming the vegetables containing oxalic acid (Simopoulos et al., 1992; Palaniswamy et al., 2004).

Ecological factors, fertilizing, growing conditions and genetic factors affect plant development and their chemical content (Palaniswamy et al., 2000). Purslane is grown in gardens in March-September when insolation is frequent albeit varying by ecologies and can be grown in greenhouses when soil and field conditions are not appropriate. In addition, greenhouse cultivation is carried out for healthier and homogeneous plant growth against the possible negative effects of diseases and pests, rain and wind (Pandey and Pandey, 2015). It is not very competitive against other plants. Plant development gets weaker in shady medium and scraggily developing plants are not durable against diseases and pests. When external conditions do not allow plant development, growing the plant in greenhouses provides advantages for both competition against other species and plant development. In soilless systems, the growing medium affects the plant length, dry and wet weights as well as crude fiber, protein, lipid and ash contents (Alu'datt et al., 2019). In soilless growing, certain organic and inorganic based media are used. Humic acid has effects such as inducing useful microorganisms in addition to the features of chelation, buffering, cation exchange capacity and nutrient ingestion in the growing medium (Abdel-Razzak and El-Sharkawy, 2013). Use of humic acid is preferred in soil and soilless plant growing due to its direct and indirect effects in plant development. In this study, effect of humic acid applications in peat and perlite mixtures of different ratios on plant development and certain chemical contents of purslane.

\section{Material and Methods}

\section{Plant material and equipment}

In the study, standard seeds of Salonica purslane species (Istanbul Seed) were used. The plants were grown under maximum/minimum temperatures of $26 / 15^{\circ} \mathrm{C}$ in greenhouse conditions. Plants were grown in plastic pots $50 \times 20 \times 17 \mathrm{~cm}$ in size and 11 liters in volume.

\section{Growing medium}

Different mixture ratios of perlite (Akper Mining Co., Çankiri/Turkey) and peat (Basissubsrat 2, Stender Group, Germany) medium was used in the study. These media are given below (Table 1).

Seeds were homogenously sown on the media filled to sowing pots with a calculation of $0.6 \mathrm{~g}$ per square meters on April 6. Following the sowing, seeds were coated with a covering material (peat) of $1 \mathrm{~cm}$ height. Plant development in pots was left to its natural course, and no number of plants was equalized. 
Table 1. Growing media and its contents

\begin{tabular}{c|c}
\hline Media & Contents \\
\hline Medium 1 & Peat (100\%) \\
Medium 2 & $2: 1$ Peat:Perlite \\
Medium 3 & $1: 1$ Peat:Perlite \\
Medium 4 & $1: 2$ Peat:Perlite \\
Medium 5 & Perlite (100\%) \\
\hline
\end{tabular}

\section{Humic acid applications and fertilizing}

HumElit 18 (Kutahya Chemical, Turkey) humic acid of leonardite origin was used in the study. Humic acid was applied by providing irrigation water following the seed sowing. $0.1 \%, 0.2 \%, 0.3 \%$ and control solutions (water) of humic acid were used as testing factor and the prepared solutions were applied with a calculation of $2.500 \mathrm{cc}$ per $\mathrm{m}^{2}$. As chemical fertilizer, 10-8-10 kg of N-P-K (Nitrogen, Phosphorus and Potassium) was fertilized per decare. Nitrogenous (CAN- calcium ammonium nitrate) and potassic (potassium sulfate) fertilizers were used evenly in two times on the day of seed sowing and $15^{\text {th }}$ day respectively and phosphorus (TSP-triple superphosphate) fertilizer was applied once on the day of sow seeding. All cultural procedures such as weed removal and irrigation (twice a week) were duly performed till harvesting.

\section{Harvesting of the plants}

On $48^{\text {th }}$ day following the seed sowing (beginning of blooming), the plants were harvested from 1-2 cm above the root collar by means of a sharp knife. The following quality analyses were carried out on the harvested plants.

Plant yield: The harvested plants were weighed on scales of 0.01 precision and the yield was determined.

Shoot length: The distance between the butt and the growing end of 5 shoots randomly selected from each application was measured by ruler and the shoot length $(\mathrm{cm})$ was determined accordingly.

Shoot diameter: The shoots were measured from $1 \mathrm{~cm}$ above their butt by means of digital caliper and the shoot diameter $(\mathrm{mm})$ was determined by averaging these values.

Determining nitrate content: 5 grams of plant sample were crashed in a porcelain garlic press with distilled water. Inside of the garlic press was washed by using $100 \mathrm{ml}$ purified water and drained into the volumetric flask with white band filter paper and thus the samples were diluted 10 times. $0.5 \mathrm{ml}$ sample was taken into tubes from filtered agent and $1 \mathrm{ml} \mathrm{5 \%}$ salicylic acid was added and the mixture was mixed in the vortex and then cooled. After adding $10 \mathrm{ml} \mathrm{NaOH}$ solution on it, the new mixture was also mixed in the vortex and then cooled. Then, the samples were read at a wavelength of $410 \mathrm{~nm}$ via the spectrophotometer and nitrate nitrogen of the plant was determined (Cataldo et al., 1975).

Determining oxalic acid values: The oxalic acid content was discovered via the spectrophotometer by Victoria Blue B indicator. $4 \mathrm{ml}$ of paint solution, Victoria Blue B $\left(1 \times 10^{-4} \mathrm{~mol} / \mathrm{L}\right)$ solution, potassium dichromate solution $(0.030 \mathrm{~mol} / \mathrm{L})$ and sulfuric acid solution were taken and a mixture of $100 \mathrm{ml}$ was obtained and this mixture was awaited under a water bath of $600{ }^{\circ} \mathrm{C}$ for 9 minutes after mixing it thoroughly and then cooled under tap water for 2 minutes. 20 hours before the reading, 0.05 grams of dry and ground purslane was put in plastic test tubes of $50 \mathrm{ml}$ and $50 \mathrm{ml}$ distilled water was added onto it. Half an hour before the reading, it was awaited in water bath $\left(60^{\circ} \mathrm{C}\right)$ for 10 minutes 
and left for cooling. The filtrate was filtered with filter paper and then $3950 \mu \mathrm{l}$ paint solution was added onto $50 \mu \mathrm{l}$ sample taken from this filtrate. Then, the samples were awaited under a water bath of $60{ }^{\circ} \mathrm{C}$ for 9 minutes and oxalic acid was ensured to react with Victoria Blue B. Absorbance values of the samples cooled under running tap water were measured at a wavelength of $610 \mathrm{~nm}$ via the spectrophotometer without delay. Oxalic acid content was measured in $\mathrm{mg} \mathrm{g}^{-1}$ dry weight through the regression equation obtained by standard oxalic acid solutions with the known concentrations prepared in the same manner (Yan et al., 2004).

\section{Statistical analysis}

The study was based on three repetitions according to the random plots trial design. The data were statistically analysed through JUMP packaged software. Each pot was considered to be an application repetition. The meaningful differences between applications and interaction values were determined to have a $p<0.05$ level of significance in LSD multiple comparison test. Since all interaction effects were found to be insignificant, application effects were discussed separately.

\section{Results and Discussion}

\section{Plant yield}

Effect of growing media and humic acid doses on plant yield of purslane given Figure 1.
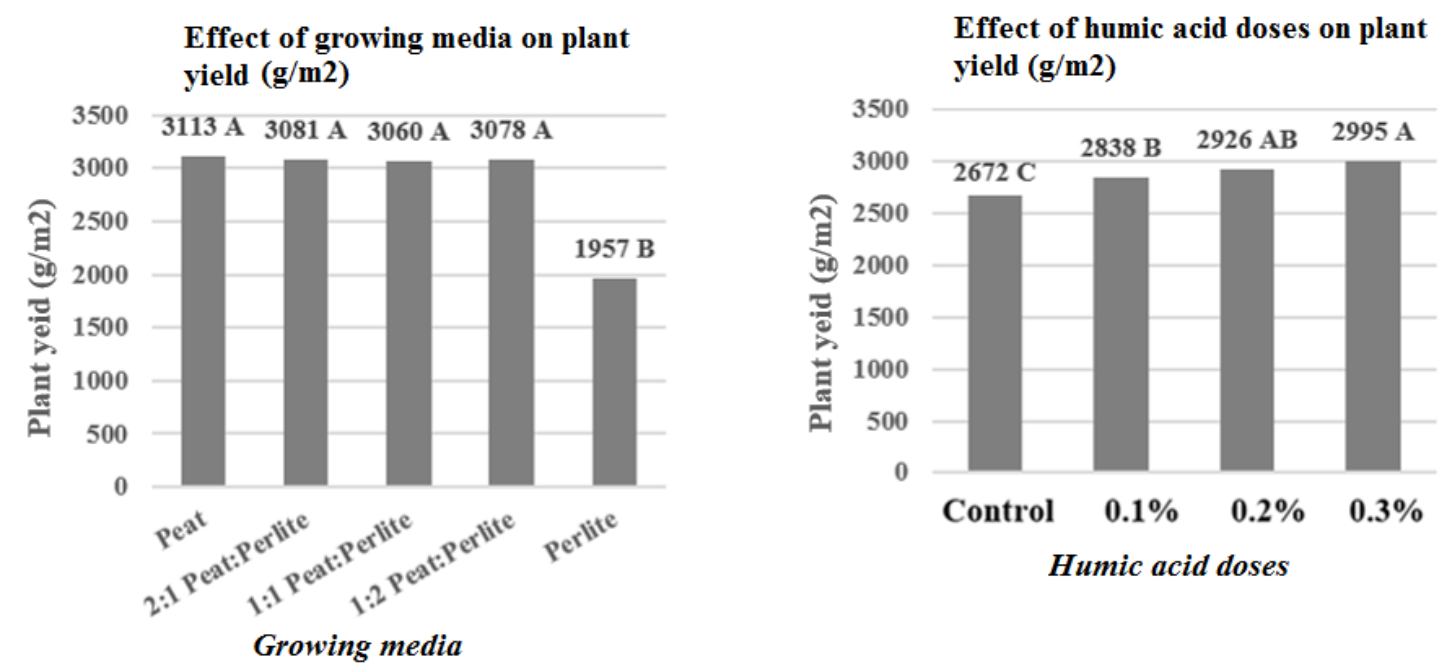

Figure 1. Effect of growing media and humic acid doses on plant yield of purslane. Different letters on the column indicate significant differences at $P<0.05$ according to LSD test

In the study, growing media and humic acid doses led to changes in plant yields of the purslane plants. Scrutinizing the plant yields by growing media, all peat-containing mixtures were included in the same statistical group and had higher plant yields compared to the perlite medium. Plant yields of the plants growing in the perlite yield decreased by up to $36 \%$ compared to those grown in other growing medium. It was determined by Cros et al. (2007) in their studies testing the effects of different growing medium for purslane that plant yield decreased by $53 \%$ in the perlite medium compared to the peat medium. 
Sezer and Ugur (2016) reported that the highest and lowest plant yields were obtained in peat medium and perlite medium respectively for the red sorrel plants grown in different growing media. Kaymak (2013) found out that plant yield of different nitrogen sources for the purslane varied between $1295 \mathrm{~g}$ and $1524 \mathrm{~g}$ per square meter. Similarly, Fontana et al. (2006) established that rational change and quantity of different nitrogen sources changed plant yield of purslane by $714-1807 \mathrm{~g}$ per square meter. Karkanis and Petropoulos (2017) reported that plant yield of purslane genotypes per square meter varied 1523 to $2800 \mathrm{~g}$. In the previous studies, lower plant yields were found out for the perlite medium compared to organic growing medium in terms of growing of different vegetable species. It is considered that perlite is less effective for plant development compared to media of organic origin as it is an inert (chemically inactive agent) medium. Due to this reason, plant yield was identified to be lower in the perlite medium compared to peat and peat-mixture media. On the other hand, harvesting time is another factor affecting the plant yield of green vegetables. In our study, the plant was harvested on the $48^{\text {th }}$ day following the seed sowing. Hence the purslane plants were harvested on the $20^{\text {th }}$ day following the seed sowing in the study conducted by Fontana et al. (2006) which gave lower plant yield values. In the meantime, it is also possible for the ecology to affect the plant yield. Indeed, Oztekin et al. (2020) stated in their study that fertilization and temperature are effective in plant yield and earliness in purslane. The fact that the plant yield was determined to be 1295-1524 g per square meters in the study conducted by Kaymak (2013) in Erzurum province that has a harsher climate compared to Merzifon (Amasya) where we grew purslane indicates that the ecology directly affects plant development. Application doses of humic acid also affected the plant yields. As the application doses increased, so did the plant yields. A humic acid dose of $0.3 \%$ gave us the highest plant yield. As humic acid increases water and nutrient ingestion from the soil, positively affects the useful organisms on the soil, induces enzyme activities and growing hormones due to its general characteristics higher plant yield values were obtained by application of it (Ekinci et al., 2015).

\section{Shoot length}

Effect of growing media and humic acid doses on shoot length of purslane given Figure 2.
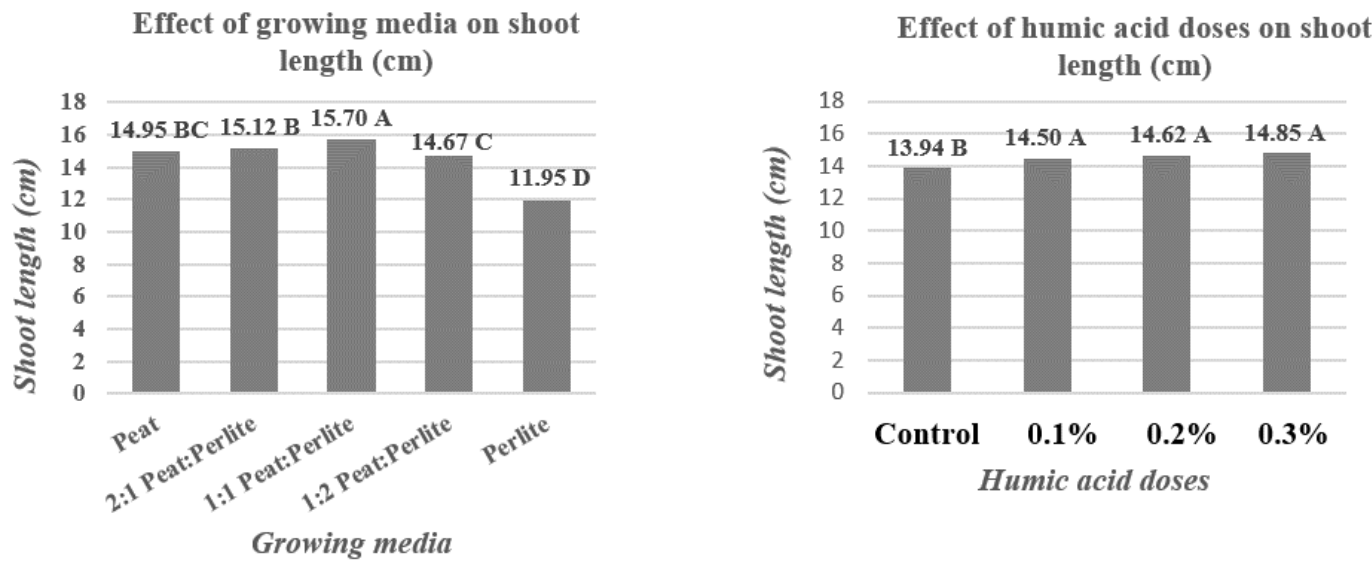

Figure 2. Effect of growing media and humic acid doses on shoot length of purslane. Different letters on the column indicate significant differences at $P<0.05$ according to LSD test 
It was observed that there were statistical differences in the shoot length of the purslane plants by the growing media and humic acid applications $(\mathrm{p}<0.05)$. Humic acid applications were included in the same group statistically and increased the shoot length compared to the control. The best results in terms of shoot length of the growing media were obtained from 1:1 peat/perlite mixture and it was identified that it yielded a shoot length approximately $31 \%$ higher than the perlite medium. Considering the shoot lengths in terms of growing medium, it was observed that the perlite medium and 1:1 peat/perlite medium yielded the worst and best results respectively. The peat medium and peatcontaining media yielded higher shoot lengths compared to the perlite medium. This is not only related to peat but also caused by its ventilation and water retention properties compared to the perlite medium. Sezer and Ugur (2016) reported that the peat medium yielded increases up to $142-151 \%$ for the leaf stalk length of red sorrel compared to the perlite medium. This, as stated before, is related to the fact that peat is a medium of organic origin and allows using nutrients more.

Effects of the humic acid doses on the shoot length of the purslane plants were similar to those on plant yields. The lowest shoot length was determined in the control application and humic acid applications had an increasing effect on the shoot lengths. The shoot length tended to increase depending on the increase in humic acid doses but effects of the application doses were determined to be similar. However, humic acid applications were found out to be non-effective on the plant development. In such studies, causes such as the application method, inappropriate application doses and contents of commercial preparations might prevent observation of the anticipated effect. It is clear that humic acid has positive influence on the metabolism in terms of its general effects albeit varying by plant species. Scrutinizing the studies on the shoot lengths of the purslane, Egea-Gilabert et al. (2014) reported that the plant length varied 9.3 to $15.4 \mathrm{~cm}$ in commercial and local purslane genotypes. Palaniswamy et al. (2004) stated that the shoot length of the purslane was $27.4-30.7 \mathrm{~cm}$ and $41.3-44.3 \mathrm{~cm}$ in 8-leaf and 16-leaf phases respectively. Santos et al. (2016) found out that the plant length of purslane varied 10.2 to $20.4 \mathrm{~cm}$ by nitrogenous fertilizing. In our study, the shoot lengths were 11.35 to $15.81 \mathrm{~cm}$. It was observed that our shoot lengths were lower compared to similar studies. Higher plant or shoot length values measured in other studies were caused by the fact that the plants bloomed and reached to full development phase in terms of plant lengths in such studies. As the shoots were harvested prior to blooming of the plants in our study, the plant shoots did not reach to their final forms.

\section{Shoot diameter}

Effect of growing media and humic acid doses on shoot diameter of purslane given Figure 3.

It was found out that the growing media and humic acid applications led to statistically meaningful changes in the shoot diameters of the purslane $(p<0.05) .2: 1$ peat/perlite medium yielded the highest shoot diameter of $3.88 \mathrm{~mm}$ and the lowest shoot diameter of $2.98 \mathrm{~mm}$ was measured in the perlite medium. In our study, the shoot diameters of the purslane varied 2.87 to $4.17 \mathrm{~mm}$. Petropoulos et al. (2015) stated in their researches on different purslane genotypes that the shoot diameter varied 6.21 to $10.65 \mathrm{~mm}$. It is clear that these findings are much higher than the results of our study. This margin is caused by the fact that Petropoulos et al. (2015) measured the plants in the further growing phases of the plants. Scrutinizing the shoot diameter values by growing medium, the perlite medium yielded the lowest values as was the case in the shoot length. The peat/perlite 
(2:1) mixture yielded the highest shoot diameter and it was followed by the peat and peat/perlite (1:1) mixture. As indicated by Cros et al. (2007), purslane's yielding the best and worst plant development results in the peat and perlite media respectively is consistent with our findings. The peat/perlite (2:1) mixture's yielding the highest shoot diameter might be caused by plants' growing a tad slower in the peat medium thanks to ventilation provided by perlite. Shoot diameter of the purslane was directly affected by the humic acid application. Humic acid applications ensured increases up to $10 \%$ in the shoot diameter values compared to the control. A humic acid dose of $0.3 \%$ yielded the highest shoot diameter value of $3.74 \mathrm{~mm}$. Existence of more dominant/binding testing factors depending on the application purpose may prevent observing possible effects of humic acid. Hence, it was difficult to determine the effects of humic acid applications on germination due to higher germination results observed in the germination study conducted by the researches with a seed of stronger vigor.
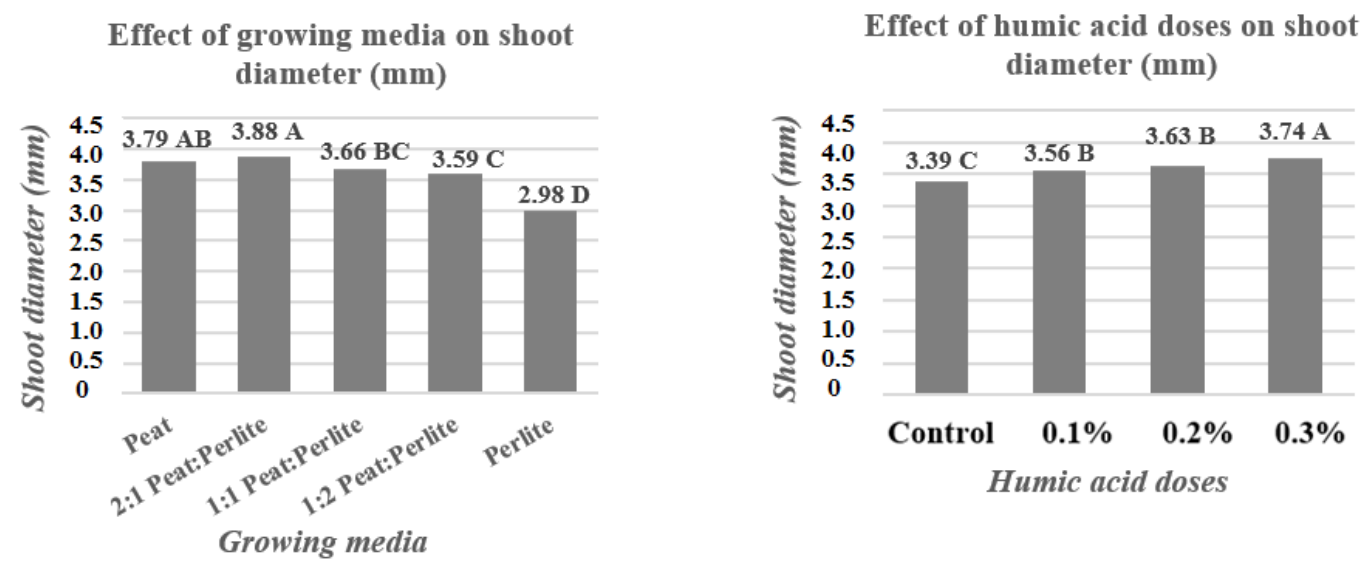

Figure 3. Effect of growing media and humic acid doses on shoot diameter of purslane. Different letters on the column indicate significant differences at $P<0.05$ according to LSD test

\section{Leaf oxalic acid values}

Effect of growing media and humic acid doses on leaf oxalic acid values of purslane given Figure 4.

Humic acid application doses and growing media were determined to effect change of oxalic acid contents of the purslane plants $(\mathrm{p}<0.05)$. The lowest oxalic acid content was measured in control plants and the plants on which humic acid doses of $0.2 \%$ and $0.3 \%$ were applied yielded the highest oxalic acid content. These results are backed by the findings of Palaniswamy et al. (2004) indicating that oxalic acid content of purslane was higher by use of nitrate fertilizers and in early development phase of the plant. On the other hand, the researches stated that oxalic acid content of $622.5 \mathrm{mg} / 100 \mathrm{~g}$ in the leaves of plantlets was reduced down to $148.8 \mathrm{mg} / 100 \mathrm{~g}$ in case of late harvesting. Egea-Gilabert et al. (2014) found out that oxalic acid content of the purslane genotypes was $155-274 \mathrm{mg} / 100 \mathrm{~g}$. It was established in the study conducted by Petropoulos et al. (2015) in Greece with 6 purslane genotypes that oxalic acid content was 371-753 mg/100 g. It was discovered in the study carried out by Kaskar et al. (2008) that the purslane genotypes of Turkish and Spanish origin had oxalic acid contents of 450.28-615.40 mg/100 g. Making a more general assessment, Moreau and Savage (2009) stated that oxalic acid content of vegetables, hard-shells, fruits and wild plants varied in a large range. 
According to the statements of the researches, plants had oxalic acid contents varying by 225 to $1294 \mathrm{mg} / 100 \mathrm{~g}$. The findings of our study seem to be consistent with Petropoulos et al. (2015). Similarly, the value of $622.5 \mathrm{mg} / 100 \mathrm{~g}$ determined for early plant development by Palaniswamy et al. (2004) resembles to the findings of our study to a great extent. It is believed that the plants of Egea-Gilabert et al. (2014) yielded lower oxalic acid contents as they had higher biomasses at the harvesting time and their shoots had harder tissues. This belief is supported by the conclusion of "decreasing oxalic acid content in purslane in late harvests" (Palaniswamy et al., 2004). At the same time, the suggestion of Moreau and Savage (2009) regarding possible effects of growing conditions on oxalic acid content of purslane may help us explaining the effects of the growing medium. Although higher oxalic acid contents were measured for the plants grown in the peat medium providing faster plant development, lower oxalic acid content of the plants grown in 2:1 peat/perlite medium compared to those grown in 1:2 peat/perlite medium makes it more difficult to reach to a definite conclusion. We believe that increase in oxalic acid content of purslane depending on humic acid application doses is related to plant development rate. High doses of humic acid may cause a decrease in oxalic acid content, as the plants are in more active growth due to the increase in mineral and water uptake to the plant. The oxalic acid content determined by Moreau and Savage (2009) in plants growing under sunny $(10.72 \mathrm{mg} / \mathrm{g})$ and shady $(12.34 \mathrm{mg} / \mathrm{g})$ conditions partially supports our suggestion.
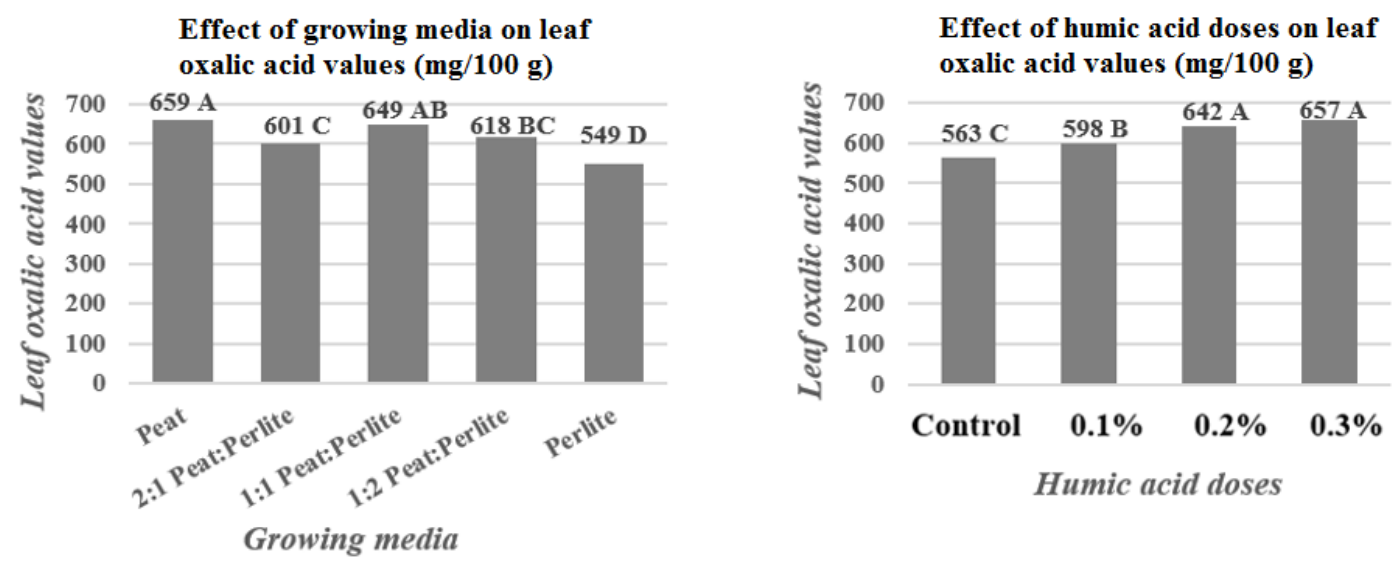

Figure 4. Effect of growing media and humic acid doses on leaf oxalic acid values of purslane. Different letters on the column indicate significant differences at $P<0.05$ according to LSD test

\section{Leaf nitrate values}

Effect of growing media and humic acid doses on leaf nitrate values of purslane given Figure 5.

Although nitrate accumulation of purslane increased in direct proportion to the humic acid application dose, this increase was determined to be statistically insignificant. Considering the nitrate accumulation by growing medium, nitrate accumulation was measured to be lower in the peat-containing media. In our study, the plants grown in 1:1 peat/perlite medium yielded the lowest nitrate accumulation in terms of media. Corre and Breimer (1979) stated that purslane should be classified as a highly nitrogenous vegetable with its nitrate content higher than $2500 \mathrm{mg} / \mathrm{kg}$ in terms of wet weight. Kaskar et al. (2008) reported that the nitrate content varied 1285 to $2552.84 \mathrm{ppm}$ 
$(128.5-255.28 \mathrm{mg} / 100 \mathrm{~g})$ in the purslane genotypes of Turkish and Spanish origins. EgeaGilabert et al. (2014) established a nitrate accumulation of $1.13-3.95 \mathrm{~g} / \mathrm{kg}$ in the purslane. Franco et al. (2011) stated that the nitrate content of purslane under salty condition was $101.7-188.6 \mathrm{mg} / 100 \mathrm{~g}$ and nitrate content increased depending on the decrease in light exposure. On the other hand, Kaymak (2013) reported that nitrate content of purslane varied by nitrogenous fertilizer form and such fertilizers led to more nitrate accumulation in the plants compared to urea and ammonium fertilizers. In this study, nitrate content of the purslane was measured to be $123.2-143.5 \mathrm{mg} / 100 \mathrm{~g}$. Our results seem to be a tad higher than the previous findings. We believe that nitrate accumulation was a bit higher in our study as it was carried out in April-May that had less light exposure compared to the summer months. The nitrate accumulation determined to be $144.3-243.3 \mathrm{mg} / 100 \mathrm{~g}$ according to the results of our study resembles to the results of the previous studies to a great extent.
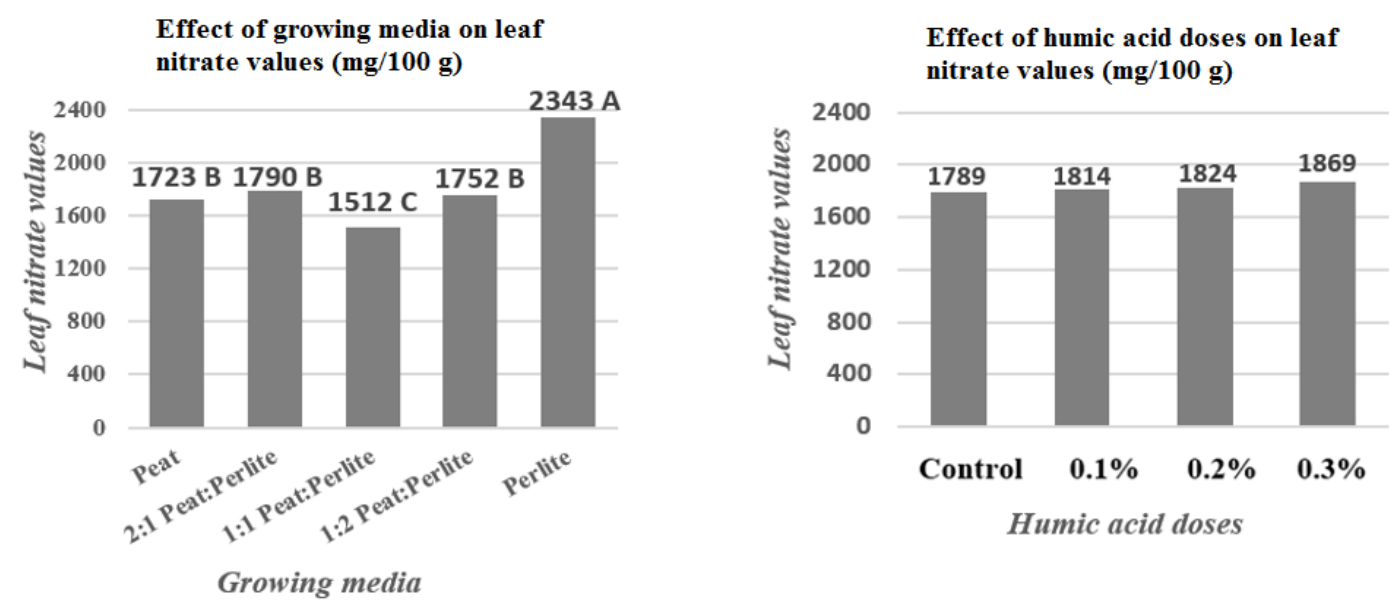

Figure 5. Effect of growing media and humic acid doses on leaf nitrate values of purslane. Different letters on the column indicate significant differences at $P<0.05$ according to LSD test

\section{Conclusions}

In the study, no significant problem was observed for purslane growing under the greenhouse conditions of our region in terms of diseases and pests. As we grew these plants in a mid-season, plant development was affected and it was observed that the plants tended to bloom to create seeds as the temperature increased. Yield and leaf quality of the plants vary by the growing medium. The growing media other than $100 \%$ perlite produced similar yield values. 1:1 peat/perlite mixture stood out by its yield values, low nitrate and oxalic acid contents and certain quality parameters such as generating long and fresh shoots (lower shoot diameter). When the perlite medium, known for its chemical inertness, was used alone, worse yielding and quality results were obtained but it might be useful to use it as a growing medium for the soilless culture as it has positive effects in terms of low concentration, physical flexibility, low heat transmission and especially water retention and medium ventilation when used with peat. As a result of this study, use of 1:1 peat/perlite mixture as the growing medium and a humic acid dose of $0.3 \%$ for growing are recommended for agricultural sustainability, productivity and a healthy growing process. However, testing genotypes at higher humic acid doses according to different growing periods and harvest times may allow for a better understanding of the subject. 
Acknowledgements. The authors thank the Ordu University Scientific Research Projects Coordination Unit for their support within the scope of the project numbered TF-1233.

\section{REFERENCES}

[1] Abdel-Razzak, H. S., El-Sharkawy, G. A. (2013): Effect of biofertilizer and humic acid applications on growth, yield, quality and storability of two garlic (Allium sativum L.) cultivars. - Asian Journal of Crop Science 5: 48-64.

[2] Alu'datt, M. H., Rababah, T., Alhamad, M. N., Al-Tawaha, A., Al-Tawaha, A. R., Gammoh, S., Ereifej, K. I., Al-Karaki, G., Hamasha, H. R., Tranchant, C. C., Kubow, S. (2019): Herbal yield, nutritive composition, phenolic contents and antioxidant activity of purslane (Portulaca oleracea L.) grown in different soilless media in a closed system. Industrial Crops and Products 141: 111746.

[3] Cataldo, D. A., Haroon, L. E., Schrader, L. E., Youngs, V. L. (1975): Rapid colorimetric determination of nitrate in plant tissue by nitration of salicylic acid. - Communications in Soil Science and Plant Analysis 6: 71-80.

[4] Corre, W. J., Breimer, T. (1979): Nitrate and nitrites in vegetables. - Pudoc, Wageningen, Netherlands, p. 75.

[5] Cros, V., Sánchez, J. J. M., Franco, J. A. (2007): Good yields of common purslane with a high fatty acid content can be obtained in a peat-based floating system. - HortTechnology 17: $14-20$.

[6] Dkhil, M. A., Abdel Moniem, A. E., Al-Quraishy, S., Saleh, R. A. (2011): Antioxidant effect of purslane (Portulaca oleracea) and its mechanism of action. - Journal of Medicinal Plant Research 5(9): 1589-1563.

[7] Egea-Gilabert, C., Ruiz-Hernández, M. V., Parra, M. A., Fernández, J. A. (2014): Characterization of purslane (Portulaca oleracea L.) accessions: suitability as ready-to-eat product. - Scientia Horticulturae 172: 73-81.

[8] Ekinci, M., Esringu, A., Dursun, A., Yildirim, E., Turan, M., Karaman, M. R., Arjumend, T. (2015): Growth, yield, and calcium and boron uptake of tomato (Lycopersicon esculentum L.) and cucumber (Cucumis sativus L.) asaffected by calcium and boron humate application in greenhouse conditions. - Turkish Journal of Agriculture and Forestry 39(5): 613-632.

[9] Fontana, E., Hoeberechts, J., Nicola, S., Cros, V., Palmegiano, G. B., Peiretti, P. G. (2006): Nitrogen concentration and nitrate/ammonium ratio affect yield and change the oxalic acid concentration and fatty acid profile of purslane (Portulaca oleracea L.) grown in a soilless culture system. - Journal of the Science of Food and Agriculture 86: 2417-2424.

[10] Franco, J. A., Cros, V., Vicente, M. J., Martínez-Sánchez, J. J. (2011): Effects of salinity on the germination, growth, and nitrate contents of purslane (Portulaca oleracea L.) cultivated under different climatic conditions. - The Journal of Horticultural Science and Biotechnology 86(1): 1-6.

[11] Karkanis, A. C., Petropoulos, S. A. (2017): Physiological and growth responses of several genotypes of common Purslane (Portulaca oleracea L.) under Mediterranean semi-arid conditions. - Notulae Botanicae Horti Agrobotanici Cluj-Napoca 45(2): 569-575.

[12] Kaskar, C., Fernández, J. A., Ochoa, J., Niñirola, D., Conesa, E., Tuzel, Y. (2008): Agronomic behaviour and oxalate and nitrate content of different purslane cultivars (Portulaca oleracea) grown in a hydroponic floating system. - Acta Horticulture 807: 521526.

[13] Kaymak, H. C. (2013): Effect of nitrogen forms on growth, yield and nitrate accumulation of cultivated purslane (Portulaca oleracea L.). - Bulgarian Journal of Agricultural Science 19: 444-449. 
[14] Moreau, A. G., Savage, G. (2009): Oxalate content of purslane leaves and the effect of combining them with yoghurt or coconut products. - Journal of Food Composition and Analysis 22: 303-306.

[15] Mousavi, S. R. J., Niazmand, R., Shahidi Noghabi, M. (2015): Antioxidant activity of purslane (Portulaca oleracea L.) seedhydro-alcoholic extract on the stability of soybean oil. - Journal of Agricultural Science and Technology 17: 1473-1480.

[16] Oztekin, G. B., Uludag, T., Tuzel, Y. (2020): Impact of nutrient solution concentration on baby leaf purslane production in floating system. - Acta Horticulture 1273: 65-74.

[17] Palaniswamy, U. R., McAvoy, R. J., Bible, B. B. (2000): Omega-3-fatty acid concentration in Portulaca oleracea is altered by nitrogen source in hydroponic solution. - Journal of the American Society for Horticultural Science 125(2): 190-194.

[18] Palaniswamy, U. R., Bible, B. B., McAvoy, R. J. (2002): Effect of nitrate: ammonium nitrogen ratio on oxalate levels of purslane. - Trends in New Crops and New Uses 11(5): 453-455.

[19] Palaniswamy, U. R., Bible, B. B., McAvoy, R. J. (2004): Oxalic acid concentrations in Purslane (Portulaca oleraceae L.) is altered by the stage of harvest and the nitrate to ammonium ratios in hydroponics. - Scientia Horticulturae 102(2): 267-275.

[20] Pandey, S., Pandey, A. (2015): Greenhouse technology. - International Journal of Research-Granthaalayah 3(9): 1-3.

[21] Petropoulos, S. A., Karkanis, A., Fernandes, A., Barros, L., Ferreira, I. C., Ntatsi, G., Petrotos, K., Lykas, C., Khah, E. (2015): Chemical composition and yield of six genotypes of common purslane (Portulaca oleracea L.): an alternative source of Omega-3 fatty acids. - Plant Foods for Human Nutrition 70(4): 420-426.

[22] Petropoulos, S. A., Karkanis, A., Martins, N., Ferreira, I. C. F. R. (2016): Phytochemical composition and bioactive compounds of common purslane (Portulaca oleracea L.) as affected by crop management practices. - Trends in Food Science \& Technology 55: 1-10.

[23] Santos, R. V., Machado, R. M. A., Alves-Pereira, I., Ferreira, R. M. A. (2016): The influence of nitrogen fertilization on growth, yield, nitrate and oxalic acid concentration in purslane (Portulaca oleracea). - Acta Horticulture 1142: 299-304.

[24] Sezer, M., Ugur, A. (2016): The effect of growing medium and organic fertilizing on some yield properties of the sorrel (Rumex acetosella L.). $-6^{\text {th }}$ International Conference of Ecosystems, June 2-6, Tirana, Albania.

[25] Simopoulos, A. P., Norman, H. A., Gillapsy, J. E., Duke, J. A. (1992): Common purslane: A source of omega-3 fatty acids and antioxidants. - Journal of the American College of Nutrition 11: 374-382.

[26] Yan, Z. Y., Xing, G. M., Li, Z. X. (2004): Quantitative determination of oxalic acid using victoria blue $B$ based on a catalytic kinetic spectrophotometric method. - Microchimica Acta 144(1-3): 199-205. 